\title{
A Matemática no Direito de Propriedade da União 351.711:51
}

\section{Nelson Nascimento Santos}

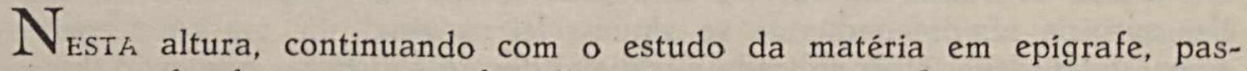
samos a abordar os casos de alienação e remissão de terrenos pertencentes à União. Alienação - A alienação, salvo os casos em contrário expressos em lei, é feita em concorrência pública, em obediência a estatutos legais; dá-se para a transferência do direito ao domínio pleno e, excepcionalmente ao de dominio útil se se tratar de terrèno de interior, isto é, não de marinhas. Para os terrenos de marinhas o objeto da concorrência pública é a transferência do direito ao dominio útil, ressalvados aqui os antigos atoramentos de terrenos de interior e aquêles que dizem respeito ao Decretolei $n^{2}$ S93, de 26 de novembro de 1938, geralmente aplicável à Fazenda Nacional de Santa Cruz.
\end{abstract}

\section{ALIENAÇÃo DE IMÓVEL DA UNIÃO}

\section{a) Terrenos de interior}

A alienação de terreno de interior ocorre «quando não houver interêsse econômico de manter o imóvel ou melhor, o terreno de interior com benfeitoria (prédio) no domínio da União, nem inconveniente quanto à defesa nacional, no desaparecimento do vínculo da propriedade» na conformidade dos artigos 134 e 135 do capítulo I do título III do Decreto-lei $\mathrm{n}^{\circ} 9.760$ de 5-9-946 (D.O. de 6-9-46), que trata dos Bens Imóveis da União.

Autorizada a alienação pelo legislativo, avaliado o domínio pleno do terreno com benfeitorias (o que é de exclusiva competência do Serviço do Patrimônio da União), a concorrência pública ao imóvel concorrido far-se-á por preço nunca inferior ao seu valur venal, vale dizer, nunca inferior ao preço médio da zona, obtido em obediência à lei da oferta e procura no mercado imobiliário, devidamente atualizado.

Assim, se chamarmos de «V» êsse valor venal e de «p» $e$ «b» respectivamente os valores do dominio pleno do terreno e das benfeitorias suportada pelo mesmo, a equação.

$$
\mathrm{V}=\mathrm{p}+\mathrm{b}
$$

dārá o preço mínimo, básico da concorrência. 
Não cabe aqui comentário de como se alcançam os valores «p»e «b» ern função dos valores unitários tirados da lei da oferta e procura no mercado de imóveis da zona, do que trataremos em local e ocasião oportunas.

A análise da equação (12) leva-nos à mais uma regra relativa ao trabalho em epigrafe, no que toca à alienação ou seja:

$7^{\text {a) }}$ O preço da alienação do dominio pleno de um terreno com benleitotras, para ef̧eito de concorrência pública, não pode ser inferior ao preço do valor atual de veindó dêsse imóvel, avaliado com fundamento nos valotes unitários extraidos das trìnsações circunvizinhas na zona, efetuadas de acôrdo com a lei da oferta e procura, ou seja, tendo em vista a rentabilidade máxima do mesmo em função do gabarito fixađ̆o pela prefeitura, que se coadune com essa lei.

Realmente, conforme estabelece o citado artigo 135, «in verbis»:

«Art. 135. A alienação de imóvel da União, uma vez autorizada, se fará em concorrência pública e por preço não inferior ao seu valor atualizado, fixado pelo S.P.U., salvo nos casos especialmente previstos neste decreto-lei».

não se pode adotar outro valor a não ser o de venda, que deve estar em consonância com o valor médio unitário dos preços de venda dos terrenos próximos daqueles que se avalia, em obediência ao parágrafo segundo do artigo nono do Decreto-lei $n^{\circ} 3.438$, de 17-7-941 (D.O. de 22-7-941), «verbis»:

« 2 $2^{9} \quad$ Para a avaliação do terreno levar-se-á em consideração as características que the são próprias, sua situação e os preços de vendas recentes de terrenos próximos».

Êste último dispositivo legal coaduna-se com o artigo 135 do Decretolei n. ${ }^{\circ} 9.760$ de $5-9-46$, de modo que outro proceder seria em detrimento dos altos interêsses da União.

$\mathrm{Na}$ equação (12), concluindo, os valores de «p» $e$ «b» devem, pois, ser atuais e venais, tendo em vista o aproveitamento máximo do terreno e de locação da benfeitoria de acôrdo com o último gabarito e preço de locação unitário, nos prédios circunvizinhos.

\section{b) Terrenos de marinha}

A alienação do direito preferencial ao aforamento é feita, igualmente, em concorrência pública, obedecendo ao artigo 111 do Decreto-lei 9.760, de 5-9-46, que preceitua:

Art. 111. A alienação do direito ao aforamento se fará em concorrência pública, por preço não inferior à importância de $80 \%$ (oitenta por cenio) do valor do domínio pleno.

$\mathrm{Na}$ alienação do direito preferencial ao aforamento, como se infere da própria indole do aforamento, o que se aliena é o direito líquido e certo ao atoramento do terreno, virgem de benfeitorias, ficando o ganhador da con- 
corrência pública sujeito à sua regularização. $O$ que está em concorrência é, pois, o dominio útil do terreno, cujo valor é dado em função do valor do domínio pleno do mesmo, pela equação (6) anterior, aqui repetida:

$$
u=0,83 p
$$

Esta equação leva nos a admitir, «permissa venia», engano do legislador ao expressar o espirito do artigo 111 do Decreto-lei $n^{\circ} 9.760$ de 5-9-946, por isso que, data venia, a hipótese da aproximação por falta ao estipular apenas 0,80 p para o minimo de licitação permitida, não seria cabível para terrenos de grande valor. Por exemplo, o êrro que se cometeria alienado um terreno (domínio útil) de dez milhões de cruzeiros de domínio pleno por oito milhões de cruzeiros, em vez de oito milhões e trezentos mil cru zeiros, isto é, tomando a fórmula 0,80 p em vez de 0,83 p, seria de trezentos mil cruzeiros. Este fato nos leva a, por isso, admitir que a intenção do legislador foi estabelecer, em palavras, $u=0,83 p$ conforme a equação (6) a que já nos referimos, parecendo nos incorreta, ainda que legal, a adoção de $u=0,80 p$.

De passagem ressalte-se aqui que as determinações de «p» $e$ «b», das equações anteriores, são feitas pelos métodos usuais de avaliação; se porém forem empregados os métodos de JERRET, de HARPER ou similares, para que se não fuja do espírito dos dispositivos legais de alienação aqui invocados, mister se torna que o valor do fundo base seja deduzido de valores de terreno da zona correspondentes aos seus aproveitamentos máximos, de acôrdo com os últimos gabaritos (horizontais e verticais) de construção, impostos pelos podêres competentes municipais.

O métọdo mais aconselhável, porém, na fixação de «p» $\mathrm{e}$ «b» é aquêle do valor residual do terreno e do custo de reprodução das benfeitorias, toniando-se a devida cautela quanto à taxa de capitalização do terreno e de depreciação anual da benfeitoria, do que trataremos oportunamente por aqui não ser lugar propício.

Sempre que o objeto de alienação seja o direito preferencial ao domínio útil entăo o desdobramento da equação (12) em sucessivamente $\mathrm{p}=\mathrm{V}-\mathrm{b}$ (13) $\mathrm{e} d+\mathrm{u}=\mathrm{V}-\mathrm{b}$, face à equação (1), nos fornece a equação $\mathrm{u}=\mathrm{V}-(\mathrm{d}+\mathrm{b})$, de modo que o preço minimo de licitação dado por esta expressão é:

$$
\begin{array}{lll}
\mathrm{u}=\mathrm{V}-(\mathrm{d}+\mathrm{b}) & (14) \text { ou } \\
\mathrm{u}=\mathrm{V}-(0,17 \mathrm{p}+\mathrm{b}) & (15), \text { por isso que } \mathrm{d}=0.17 \mathrm{p} \text { pela }
\end{array}
$$

equação (5), que abordamos nas primeiras considerações sôbre o título em epigrafe.

Yode-se fazer $b=0$ nas fórmulas (14) e (15), então virá $V=p$, isto é, no lugar do valor total do imóvel, toma-se apenas o valor do domínio pleno do terreno. ção (1). 
Do exposto podemos tirar as seguintes regras práticas:

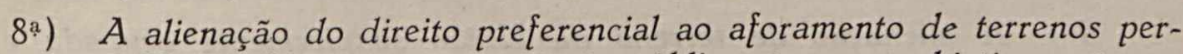
tencentes à União, teita em concorrência pública, tem por objetivo a transterência do dominio útil da mesma ao ganhador da concortência, valor de dominio êsse que é calculado tomando-se $83 \%$ do valor de dominio pleno do mesmo ( $80 \%$ dêsse, tomando-se a lei ao pé da letra), ou pela diferença existente entre o valor total do imóvel e o binômio constituido pela soma do valor das benfeitorias aos $17 \%$ do valor do dominio pleno.

A regra oitava acima, correspondem as fórmulas (6), (14) e (15) reto.

\section{c) Caso especial de alienação}

No que toca ainda à alienação ao simples ocupante do terreno da União, conforme artigo 139 do Decreto-lei $\mathrm{n}^{\circ} 9.760$ de 5-9-946 que preceitua:

Art. 139. O Presidente da República, por proposta do Ministro da Fazenda, poderá autorizar a alienação de terrenos da União, que se encontrem ocupados por terceiros, mediante as condições previstas neste decreto-lei.

Os terrenos da União, simplesmente ocupados, poderão ser alienados, desde que não mais lhe haja interêsse econômico em mantê-lo sob o seu dominio e nem inconveniente no desaparecimento do vinculo da propriedade, por proposta do Ministro da Fazenda e autorização do Presidente da República e para terrenos compreendidos em determinadas zonas.

É feita em concorrência pública, salvo os casos dos itens $1^{\circ}$ ao $5^{\circ}$ do artigo 105 do citado diploma legal e na forma do parágrafo $1 .^{\circ}$ do artigo 160 do mesmo, «in verbis»:

$\S 1^{\circ}$ a alienação será feita pela importância de 20 (vinte) taxas e $11 / 2$ (um e meio) laudêmio, calculado êste sôbre o valor do domínio pleno do terreno e das benfeitorias existentes.

Este dispositivo legal é traduzido para a matemática pela equação:

$$
\mathrm{V}=20 \mathrm{~T}+1.5 \mathrm{~L}
$$

Mas, pela equação, (11), $\mathrm{L}=0,05(\mathrm{p}+\mathrm{b})$, e tendo em vista o parágrafo primeiro do artigo 127 do Decreto-lei $n .^{\circ} 9.760$, de 5-9-46, verbis:

"Art. 127. Os atuais ocupantes de terreno da União, sem títula outorgado por esta, ficam obrigados ao pagamento anual da taxa de ocupação. $\S 1 .^{\circ}$. A taxa corresponde $1 \%$ (um por cento) sôbre o valor do dominio pleno do terreno»

da qual resulta mais a equação:

$$
\mathrm{T}=0,01 \mathrm{p}
$$

a equação (16) pode ser posta sob a última forma abaixo, após convenientes transformações:

$$
V=\frac{1}{40}(11 p+3 b)
$$


Esta igualdade leva-nos a mais a seguinte regra prática:

9:) A alienação de terteno da União simplesmente ocupada e sob regime de aforamento, dar-se-á, para efeito da aquisição do dominio útil, na base do valor correspondente a um quarenta avos da soma de onze vêze's o valor do dominio pleno do mesmo após acrescido do triplo do valor das benfeitorias pertdicentes ao ocupante

É óbvio que a regra supra aplica-se a terrenos sob o regime de aforamento, ocupados e sem qualquer título que possa outorgar direito preferencial ao aforamento ao seu ocupante, detentor de benfeitorias.

Contudo, mister se torna que se tenha

$$
\frac{1}{40}(11 p+3 b) \leq 0,83 p
$$

(19), o que equivale a têrmos em

última análise,

$$
\mathrm{b} \leqslant 7,4 \mathrm{p}
$$

Esta última fórmula leva-nos a mais uma regra prática:

10. Só no caso da benfeitoria, pertencente ao ocupante de terreno enfitêutico da Uniâo, ser superior a 7,4 vêzes o valor do dominio pleno do mesmo, dever-se-á aplicar a regra nona destas considerações. No caso coñtrário, aplicar-se-á a regra oitava, a fim de não prejudicar a União, por isso que esta apresenta valor superior ao encontrado pela outra.

Até aqui fizemos a análise matemática sôbre os princípios que regem a alienação de imóveis pertencentes a União. Depois, completando as considerações, que vimos apresentando sôbre a matéria concernente ao titulo de nossos artigos, em epígrafe, abordaremos o caso da remissão dos terrenos enfitêuticos. Antes, porém, uma vez que o cálculo de laudêmio entra tanto na alienação de terrenos simplesmente ocupados como na remissão dos a!orados, impõe-se a ampliação da análise relativa à fórmula (11), que aqui repetimos

$$
L=0,05(p+b)
$$

É que, com fundamento do parágrafo segundo do artigo 102 do Decretolei $\mathrm{n}^{\circ} 9.760$ de 5-9-946, verbis:

$\S 2^{\circ}$ No caso de terreno da União incorporado ao de outrem, de que não possa ser desmembrado, o valor das benfeitorias será tomado proporcionalmente aos valores dos mesmos terrenos, há a considerar ainda êste caso especial.

Vejamos a interpretação matemática dêste dispositivo legal.

Chamemos inicialmente de «V》 $e$ «V》 os respectivos valores dos terrenos da União e o da pessoa, sabendo que o da União: não pode ser desmembrado do outro. Representamos por «b» o valor das benfeitorias - qual deve entrar no cálculo do laudêmio e por «B» o valor total das benfeitorias existentes no terreno total indesmembrável. 
Com fundamento nesse dispositivo legal, pode-se escrever:

$$
\begin{aligned}
& \frac{\mathrm{v}}{\mathrm{v}}=\frac{\mathrm{b}}{\mathrm{B}} \\
& \mathrm{b}=\frac{\mathrm{v} B}{\mathrm{~V}}
\end{aligned}
$$

Desta equação surge a regra prática seguinte:

$11^{\text {a) }}$ O valor das benfeitorias que entra no cálculo do laudêmio do terreno da União incorporada ao de outrem e do qual não possa des membrar-se, é dado pela relação entre os valores do terreno da União para - total, multiplicado pelo valor das benfeitorias realmente existentes, avaliados pela União.

Nas mais das vêzes acontece, porém, que os valores de $\mathrm{V}$ e $\mathrm{B}$ aparecem englobadamente nas escrituras, o que acarreta a impraticabilidade da equação (21) deduzida atrás.

Para atender êsses casos freqüentes, deduzamos uma equação equivalente à (21) em que, como acontece os dados são:

$\mathrm{V}+\mathrm{B}$ ou $\mathrm{P}=$ valor do terreno transferendo com benfeitorias, pertencente à outrem.

$\mathrm{v}=$ valor do terreno da União ocupados ou aforado, por ela avaliado, dominio pleno.

Posta a equação (20) sob a forma

$$
\begin{aligned}
& \frac{\mathrm{v}}{\mathrm{b}}=\frac{\mathrm{V}}{\mathrm{B}} \quad \text { e sucessivamente } \\
& \frac{\mathrm{v}+\mathrm{b}}{\mathrm{v}}=\frac{\mathrm{V}+\mathrm{B}}{\mathrm{V}} \\
& \mathrm{v}+\mathrm{b}=\frac{\mathrm{v}}{\mathrm{V}}(\mathrm{V}+\mathrm{B}) \\
& \mathrm{v}+\mathrm{b}=\frac{\mathrm{v}}{\mathrm{V}} \quad \mathrm{P}
\end{aligned}
$$

Esta equação leva à regra seguinte:

12 ) No caso de terreno da União incorporado ao de outrem de que não possa ser desmembrado, o binômio valor de terreno e benfeitorias para - cômputo do laudêmio, é dado pelo produto da relação dos valores do terteno da União para o de outrem, pelo preço total da transferência, se êste não fôr menor que a avaliação feita pela União. 
Uma vez que o laudêmio é de $5 \%$ sôbre o valor do terreno com benteitorias, pelas equações (21) e (22) podemos estabelecer as fórmulas

$$
\begin{aligned}
& \mathrm{L}=0,05\left(\mathrm{v}+\frac{\mathrm{vB})}{\mathrm{V}}\right. \text { ou } \\
& \mathrm{L}=0,05 \mathrm{v}\left(1+\frac{\mathrm{B}}{\mathrm{V}} \quad(24) \mathrm{e}\right. \\
& \mathrm{L}=0,05 \frac{\mathrm{v}}{\mathrm{V}} \mathrm{P}
\end{aligned}
$$

Dai mais a regra seguinte:

13a) O cálculo do laudêmio de um terreno da União incorporado ao de outrem do qual se não possa desmembrar é dado pelo produto de três fatôres sendo um 0,05 , outro o valor do terreno pertencente à União e o outro o binômio constituido pela unidade acrescida da relação dos valores da benfieitoria para o valor do terreno total (da união mais do interessado na transferência); pode ser dado também pelo produto de três fatôtes, sendo um 0,05 , outro a relação entre os valores do terreno da União e total e o outro o preço total do móvel transferendo.

Ėm conseqüência, tendo em vista o caso de alienação de terreno pertencente à União, simplesmente ocupado, pode-se escrever, sucessivamente:

$$
\begin{aligned}
20 \mathrm{~T}+1,5 \mathrm{~L}=0,83 p \operatorname{mas} \mathrm{T}=0,01 \mu(17) \\
\mathrm{L}=0,05(\mathrm{v}+\mathrm{b}) \quad \text { ou } \\
\mathrm{L}=0,05(\mathrm{p}+\mathrm{b}) \\
\mathrm{b}=\mathrm{v} B \\
\overline{\mathrm{V}}
\end{aligned}
$$

Logo

$$
\begin{aligned}
& 0,20 p+1.5+0,05\left(\frac{p+v}{\bar{V}}\right) \leq 0,830 \\
& 0,075\left(p+\frac{v}{V} B\right) \leq 0,63 p \\
& 0,075 p+0,075 \vee B \quad \bar{V} \\
& 0,075 \vee 0,63 p \\
& \frac{V}{V}
\end{aligned}
$$




$$
\begin{aligned}
& \mathrm{B}=\frac{111 \mathrm{p}}{\mathrm{V}} \\
& \mathrm{B} \leq \frac{111}{15} \times \frac{\mathrm{v}}{\mathrm{V}} \quad \text { como } \mathrm{v}=\mathrm{p} \\
& \mathrm{B} \leq \frac{111}{15} \quad \mathrm{~V}
\end{aligned}
$$

Dai mais a regra:

14.3 Para que convenha à União efetuar a alienação de terteno simplesmente ocupado, no caso de estar incorporado ao de outrem do qual se nâo possa desmembrar, é preciso que o valor das benfeitorias existentes sôbre o mesmo seja superior, ou pelo menos igual a cento e onze quinze avos do valor do terreno todo, isto é, da soma dos valores dos terrenos pertenceintes à União e alodiais.

Uportunamente, voltando ao assunto em epigrafe, trataremos do caso da REMISSĀO, de muito interêsse, quer à União, quer ao foreiro. 